\title{
How Teachers Understand and Use Power in Alternative Assessment
}

\begin{abstract}
Kelvin H. K. Tan
Curriculum, Teaching and Learning Academic Group, National Institute of Education, Singapore 637616

Correspondence should be addressed to Kelvin H. K. Tan, kelvin.tan@nie.edu.sg

Received 11 October 2011; Revised 17 January 2012; Accepted 23 January 2012

Academic Editor: James P. Spillane

Copyright ( $) 2012$ Kelvin H. K. Tan. This is an open access article distributed under the Creative Commons Attribution License, which permits unrestricted use, distribution, and reproduction in any medium, provided the original work is properly cited.

"Alternative assessment" is an increasingly common and popular discourse in education. The potential benefit of alternative assessment practices is premised on significant changes in assessment practices. However, assessment practices embody power relations between institutions, teachers and students, and these power relationships determine the possibility and the extent of actual changes in assessment practices. Labelling a practice as "alternative assessment does not guarantee meaningful departure from existing practice. Recent research has warned that assessment practices in education cannot be presumed to empower students in ways that enhance their learning. This is partly due to a tendency to speak of power in assessment in undefined terms. Hence, it would be useful to identify the types of power present in assessment practices and the contexts which give rise to them. This paper seeks to examine power in the context of different ways that alternative assessment is practiced and understood by teachers. Research on teachers' conceptions of alternative assessment is presented, and each of the conceptions is then analysed for insights into teachers' meanings and practices of power. In particular, instances of sovereign, epistemological and disciplinary power in alternative assessment are identified to illuminate new ways of understanding and using alternative assessment.
\end{abstract}

\section{Introduction}

The moniker "alternative assessment" is a common refrain that is sometimes used to typify a general change from traditional assessment practices that would help achieve educational outcomes [1]. For example, critics of the limitations of traditional objective tests advocate a variety of alternative assessment practices such as performance-based assessment [2], portfolio assessment [3], classroom-based assessment [4], and authentic assessment [5].

However, the accompanying frequency and intensity of its utterances without pinpointing its precise meaning(s) should be a matter of concern. Maclellan [6] warns that the wide range of terms posited as examples or variants of alternative assessment would suggest a lack of actual consensus as to what the term actually refers to. These "alternative assessment" terms include performance assessment [7], authentic assessment Wiggins [5, 8], direct assessment [9], constructive assessment [10], and embedded assessment [11].

Such public discourse renders "alternative assessment" as a form of doublespeak, a way for any person to distance themselves away from what they dislike without alluding to something concrete and superior. The preponderance of the term results in a cacophony of voices articulating what should be avoided but at a cost of clarifying what must be emphasised.

This paper argues that the discourse of alternative assessment does not have an inherent meaning. Its meaning is derived indirectly from what it is not; that is, what it presumes to offer an alternative to, rather than what it naturally is. Alternative assessment lacks its own identity, and consequently hamstrings its own potential to offer a distinct alternative. Realistically, alternative assessment that is (mis)understood in abstract and malleable terms offers its idea and practice to different agendas. The (re)construction of alternative assessment discourse by different agendas may be appreciated from understanding how power constructs and frames learning in alternative assessment.

\section{Assessment and Power}

Assessment has been described as "a thing of power" [12, page 107], "a primary location for power relations" 
[13, page 267], and "the most political of all educational processes" [14, page 85]. Formal tests and examinations have been identified as a potent means of exercising power against students. Bourdieu [15] writes of the role and privileged position of tests and examinations in subjecting students' to the power of the academic establishment, whilst Reynolds and Trehan [13] identify the issue of power in assessment as largely being a disparity of power between teachers and students. McMahon [16] argues that vesting such absolute power in teachers conditions students to seek to please them rather than demonstrate their learning in assessment.

Boud et al. [17] identify covert forms of disciplinary power occurring when the reality of students collaborating for assessment purposes (e.g., peer assessment) is compromised through the influence of overriding assessment paradigms. The effect is that students examine themselves according to the range of outcomes unilaterally defined as legitimate by staff. Consequently, the students first learn to distrust their own judgements and then act as agents to constrain themselves.

In the context of objective type assessment methods, Paxton [18] points out that the genre of multiple-choice questions epitomises the idea of the generic student, and no allowance is made for student differences or for student autonomy. By utilising multiple-choice questions, assessors are predetermining that the knowledge in a given field can be demonstrated through restrictive means and that students should not or need not be given the option to express their fuller views on the said question. This confines the student to a closed interaction and reinforces the idea that someone else knows the answers to the question so original interpretations are not expected.

Such concerns over the exercise of power against students in assessment have led some writers to suggest alternative assessment practices. Shohamy [19] argues for more democratic forms of assessment as an alternative to the traditional approach of teachers' unilateral assessment of students. Likewise, Janisch et al. [4] argues that student ownership for learning and self-evaluation of progress to be hallmarks of alternative assessment. Such alternative assessment encourages students to be more responsible for their own learning and makes the relationship between teachers and students to be more collaborative [20].

Students given "more autonomy" in alternative assessment may nonetheless be subjected to power as long as they are aware of the teacher's prevailing authority in the assessment process. This can be illustrated in the phenomenon known as backwash where the student seeks to learn according to their perception of what the teacher desires [21]. In other words, what and how students learn depends on how they think they will be assessed [10]. It is therefore the student's perception of the teacher's assessment demands that influences student learning, rather than whether the assessment method is traditional or alternative.

In an earlier article [22], I had argued that self-assessment may discipline rather than empower students if the ways in which power is exercised over students in self-assessment practices are not first understood. Three types of power were identified in student self-assessment: sovereign, epistemological, and disciplinary power. They may be briefly described and contrasted, as follows.

2.1. Sovereign Power. The idea of sovereign power arises from the context of explaining power relationships between sovereign rulers and subjects in the general course of history. Such articulations of power characterise power in episodic and interpersonal terms [23].

A crucial point to understand is that sovereign power is an indivisible commodity at any given point in time; it cannot be shared and can only be surrendered to another individual. In such absolute terms, one is either an agent of power (an authority) or a recipient who responds to power (subject). Hence, the teacher's unilateral power over students in assessment can only be redistributed and never shared.

\subsection{Epistemological Power. Epistemological power may be} understood as power that affects teachers and students in the broader politics of institutions and hegemonies. Power in this respect exists beyond explicit interpersonal episodes or confrontations. An individual can be said to possess power without having to use it explicitly against another individual. In the context involving students in assessment, students are subjected to power all the time as long as they are aware of the teacher's prevailing authority in the assessment process.

In contrast to sovereign power, epistemological power posits that power does not exist only in teachers. Teachers themselves are subject to power and those who seek to change assessment practices for their students may encounter resistance and obstruction. Power is therefore not simply the proverbial burden that sympathetic teachers should "redistribute" in student assessment in order for students to learn freely. Power is also a constraint that has to be dealt with by teachers in order for their students to participate in the alternative assessment process.

2.3. Disciplinary Power. As opposed to the notion of sovereign power, disciplinary power studiously avoids stipulating who possesses power and how much power is present. Instead, its approach is to explore (and not explain) how power arises in different discourses without being limited to individuals (sovereign power) or to hegemonies (epistemological power).

In contrast with sovereign and epistemological power, discourse views power as productive and not solely repressive and as circulating rather than being possessed by individuals or groups of individuals [24]. While teachers may want to free themselves of power in order to self-evaluate their knowledge, the claims as to what is effective teaching by the teacher render the teacher governable by subjecting the him or her for measuring, categorising, normalising, and regulating [25]. Sovereign and epistemological power assumes that the absence of power in teacher self-evaluation affords the teacher autonomy to understand and self-value personal constructs of good teaching. In contrast, disciplinary power warns that the act of teacher self-evaluation exposes the teacher's thoughts and inadequacies and exposes them to greater disciplining and governance. 
This paper seeks to examine power in the context of different ways that alternative assessment is practiced and understood by teachers. Earlier research on teachers' conceptions of alternative assessment [26] is presented, and each of the conceptions is then probed to illuminate how power is understood and used by teachers in that respective context. Such a variation reveals the aspects or notions of power that teachers are aware of in alternative assessment. These insights into teachers' meanings and practices of power in alternative assessment are sought for illuminating new ways of understanding and using alternative assessment to enhance students' learning.

\section{The Alternative Assessment Context of the Study}

Singapore's national high-stakes assessment system is intended to perform a number of important institutional tasks such as to provide an objective and politically acceptable measure of student learning and to allocate students into different curriculum tracks and schools based on their academic performance [27]. Politicians are increasingly aware that what is taught, and how, can be indirectly asserted through the control of high-stakes assessment. Educational assessment has thus become a highly contested area as the focus of complex political, economic, and cultural expectations for change [28].

In Singapore, the centralized bureaucracy of the education system exerts its central authority in and through assessment policy by creating and perpetuating a centrally planned and common assessment framework. This common assessment framework applies to all schools in Singapore and is in turn administered by a central examination authority, the Singapore Examinations and Assessment Branch (SEAB), which is part of the Ministry of Education. As students take the same national examinations, there is the perception of a level playing field for all, regardless of their ethnic and socioeconomic status. Students' subsequent progression into schools and institutions of higher learning and placement into courses at each educational level are based on their performance in common national examinations. These are meant to reflect the notion of a common, level playing field and the principle of meritocracy.

Hence, the gateway to each level of education is guarded almost solely by examinations, rendering them high stakes. Assessment systems have been criticised for putting a premium on the reproduction of knowledge and passivity of mind at the expense of critical judgment and creative thinking. It is not surprising that the use of national high-stakes examination results as a sorting mechanism has inadvertently created much pressure (and stress), in particular on the teachers and students, resulting in their strong focus on grades and content acquisition rather than learning and holistic development [29].

A nation-wide investigation into the intellectual quality of assessment tasks in Singapore schools suggests that assessment practices by and large may not be oriented towards students' understanding. Between 2004 and 2005, a major research project was undertaken to examine the quality of teacher assignments and associated student work in Singapore schools [30]. Altogether, 6,526 samples of teachers' assessment tasks and associated student work from Primary 5 and Secondary 3 lessons in English, social studies, mathematics, science, Chinese language, malay language, and Tamil language in 59 Singapore schools (30 primary schools and 29 secondary schools) over two years (2004-2005) were collected and analysed. At the same time, classroom observations were made in order to situate the instructional and formative practices of teachers with the assessment tasks. The types of assessment tasks included daily class work, homework assignments, major assignments/projects, and teachermade tests.

These findings have prompted subsequent research on using assessment in more learning-oriented ways. Since alternative assessment is commonly denoted as any nonformal testing assessment method that purports to achieve what is denied or discouraged by formal tests and examinations [31], this has in turn led to more attention and interest on alternative assessment methods in Singapore.

Alternative assessment is commonly denoted as any nonformal testing assessment method that purports to achieve what is denied or discouraged by formal tests and examinations [31]. Revital and Miedijensky [32] recommend authentic assessment tasks that are performed in real or simulated situations in order to assess higher-order thinking skills which can arouse students' interest in learning.

In a recent nation-wide review in Singapore, the Primary Education Review and Implementation (PERI) Committee recommended various alternative assessment approaches to support learning. The PERI report recommended alternative assessment methods such as journal writing, peer observation, and practical and investigative tasks, to provide more holistic feedback for pupils, teachers, and parents to increase the level of engagement and confidence of pupils through their personal involvement in assessment and learning activities. In addition, the PERI report also recommended the alternative practice of "bite sized assessment" instead of examinations to lessen examination stress and to emphasise the potential and value of assessment for learning. However, Klenowski [33] notes that such "use of "bite-sized" modes of assessment, such as topical tests, to provide regular feedback on pupils' learning to parents' ... could lead to the issue of performance-orientated learning to the detriment of sustained and real learning" (p. 265).

It is argued that the ability of assessment, or alternative assessment, to empower students depends on how it is used and how it is understood by students. Reynold and Trehan [13] warn of participative approaches to assessment being experienced by students as a more subtle technique for disciplining. For participative assessment such as self-assessment to "realise in practice what it promises in principle, therefore, it is important to be alert to the tendencies for hierarchical relation to persist" (p. 273). Alternative assessment practices that increase students' involvement and responsibility in making their own decisions may ironically curb student empowerment by preserving existing hierarchical powers. 
This paper examines teachers' experiences of power in the context of three progressively more sophisticated conceptions of alternative assessment. These conceptions are further analysed for the variation in teachers' experiences of power within each conception.

\section{Method}

This study is a phenomenographic investigation into the variation in the qualitatively different ways that alternative assessment is experienced by primary school teachers in Singapore. Its main finding is in the form of a phenomenographic outcome space, wherein three different conceptions of alternative assessment are identified and explored.

Phenomenography has been credited as "an internationally valued educational research method since the 1970s" [34, page 295]. One of its key contributions has been the demonstration that variations in different approaches that students take to learning are related to corresponding levels of outcomes $[21,35]$. It has also been influential in the growing acceptance that students' learning is related to the context it takes place in [21] and that addressing the contextual influences of student learning is the key to improving learning outcomes [36].

Differences in ways of experiencing a phenomenon are typically described as categories of description or conceptions of that phenomena. Conceptions represent a researcher's analysis and description of variation in the pooled accounts of ways of experiencing the phenomenon. They represent the researcher's attempt to formalise his or her understanding of the participants' experiences of the phenomenon [37]. Each individual conception represents the critical aspects of one way of experiencing the phenomenon. Phenomenographic researchers typically refer to their entire set of findings for each researched phenomenon as the "outcome space."

In recent times, developments in thinking about phenomenographic research have shifted the focus to theoretical concerns and have come to be generally known as "variation theory." Variation theory signals a shift in the phenomenographic project from its descriptive orientation to more theoretical concerns [38]. In a recent publication of extensive research on applications of variation theory, Marton and Tsui [39] explain the potential of phenomenography for pedagogical approaches. Whilst previously phenomenography was understood as yielding a limited number of categories of description from which a phenomenon could be understood, Marton and Tsui [39] argue that "students understand that which they are supposed to learn in a limited number of different ways ... and that (their) research shows that teachers who pay close attention to such differences (or variations), and who can build on students' prior understanding and experiences, are better able to bring about meaningful learning for their students." (p. 194).

This study is part of a larger study (the first study) which examined the effect of professional development on the alternative assessment literacy of teachers and the consequent effect on students' intellectual outcomes in 16 primary schools
[40]. The first study was designed as a longitudinal, quasiexperimental intervention study for tracking teachers' assessment literacy over 2 school years (2006 and 2007). Primary 4 and 5 teachers of English, Chinese, science, and mathematics from these schools received ongoing, sustained professional development throughout the school year. They were engaged in a series of professional development workshops, which focused on authentic assessment task design and rubric development in their respective subjects and grade levels as an alternative assessment to semestral and national examinations. The researchers also met with the teachers in their inschool professional learning communities to discuss issues regarding the implementation of these alternative assessment tasks.

It was found that the mean scores of teachers' assessment tasks after intervention had increased substantially for all subjects, except mathematics. It was also observed that many teachers seemed to have differing interpretations of what alternative assessment meant and what such assessment was meant as an alternative to. Consequently, another study on the differences in the ways that teachers understood and used alternative assessment was initiated.

In the first study, teachers' alternative assessment tasks were rated for their intellectual quality and ranked high, moderate, or low (see [30] for details of the instrument). 13 primary school teachers from 7 different primry schools who had participated in the first study were approached and agreed to the phenomenographic study that this paper reports. This number is consistent with the recommended sample size of 15-20 interview transcripts that can be analysed at any one time $[41,42]$. The sample of 13 teachers represents the alternative assessment tasks/experiences in science, English, and mother tongue subjects. All three levels of outcomes were represented in all subjects taught in the sample. Individual interviews were conducted with each teacher using the reiterative semistructured convention of phenomenographic interviews.

Most phenomenographic research is conducted in the form of personal interviews in which respondents are led to reiterate their experience of the phenomenon. Three practices concerning the framing of questions in a phenomenographic interview were heeded.

(i) The questions are open ended so that interviewees can decide on the aspects of the question which appear most relevant to them $[43,44]$.

(ii) The questions are designed to be diagnostic in order to reveal the different ways of understanding the phenomenon within the context [45].

(iii) The phenomenographic interview focuses on the way the interviewees understand the phenomenon, and this focus is maintained throughout the interview [45]. This sustained focus is described by Marton and Booth [35] as the interviewees' "focal awareness" of the phenomenon during the interview.

The effectiveness of a phenomenographic interview depends on the ability of the interviewer to design and pose questions that may collectively increase the chances of a full 
exploration of the interviewees' understanding of the phenomenon. It calls for a variety of different questions and a variation in the employment of such questions. The (semi) structure of the interviews comprises different types of questions and planning in advance when and which of these different questions should be posed during the interviews.

The interview schedule comprises 5 main questions and a number of subsequent questions that could elaborate on each main question. The 5 main questions on the teachers' alternative assessment experience were as follows.

(1) Can you tell me what were your thoughts when designing the alternative assessment task?

(2) If you had to mentor a beginning teacher, what kind of advice would you give her on alternative task design and implementation?

(3) If you were to do it differently, how will you improve on the alternative assessment task?

(4) What kind of intellectual outcomes were you hoping to see in your students' work?

(5) Were there challenges when you tried to design your tasks differently from the usual convention?

Each interviewee was instructed to bring along artefacts of alternative assessment designs, and these artefacts were referred to during the interview. The first two questions were invitational in nature, giving the interviewer the opportunity to observe what each teacher volunteered as being important in describing their alternative assessment experience. Whilst the first two questions focus on what had happened in their experience, the third question sought to understand what the teachers understood to be desirable and important to alternative assessment which may not have occurred in their experience. The fourth question deepened the inquiry into what each teacher understood to be important about alternative assessment in relation to students' learning, whilst the final major question sought to elicit interviewees' responses on issues of power and resistance in alternative assessment.

Two broadly contrasting approaches to analyzing transcripts were identified. The contrast lies in whether priority is accorded towards the logical structure in the outcome space or whether priority is accorded towards the empirical evidence grounded in the transcripts. The first approach foregrounds structure and backgrounds the individual experiences. The second emphasises the individual's experiences from which the structure amongst the collective set of experiences of the phenomenon is discerned. These approaches can be labeled as the "structural focus" and the "transcript focus," respectively.

The approach to analyzing the transcripts was to utilize a transcript and structural focus. Both foci are relevant for their specific contexts and are useful at different points in the analysis of the transcripts.

When it came to understanding what a selected quote might mean in itself, that quote was read against its surrounding text in the original transcript. Such an approach is akin to the transcript focus. But when it came to understanding how a particular quote might relate to the existing categories of description, the quote would then be interpreted against the structure of the outcome space at that time.

The primary question which underpinned the interviews was "what was important to each teacher in his or her experience of alternative assessment?" The intention was to understand what the interviewees emphasized as being important in their individual experiences. In contrast, the analysis of the transcripts focused on the collective awareness of the thirteen teachers.

Segments in each transcript which conveyed a particular meaning or point about alternative assessment were identified. Each segment was given a tentative heading and a short summary. Recurring headings were noted and eventually categories of transcript segments with similar headings were formed. Repeated readings of the transcript segments against its category's headings changed the constitution of the categories. Categories were added or removed when they could not be substantiated by their constitutive segments.

The transcripts were first analysed in terms of participants' responses to the first four questions, and the collective data was sufficient to identify the three conceptions of alternative assessment. It was found that each participant had a sufficiently strong primary context which could be articulated within a single conception. Hence, it was possible to "distribute" the 13 participants into the three conceptions.

Gradually, a set of three distinct conceptions that could be presented in terms of a nested hierarchy was identified. The conceptions could be differentiated in terms of how each subsequent category was able to include the critical aspects of the phenomenon in the preceding category and formed a coherent set of qualitatively different conceptions which meets the phenomenographic criteria for a well structured outcome space.

The second round of analysis focused on responses to the fifth question. Participant's responses to the fifth question were categorised into the three conceptions. These segmented transcripts were analysed within each group for distinctive characteristics. Recurring themes were noted, and reiterative checking of labels against transcripts gradually enabled that the identification of labels for each way power was understood in each conception of alternative assessment.

The label "conformist" in the first conception of AA was used to depict recurring phrases such as "must follow," "cannot change," and "no discretion" in the relevant transcripts. For the second conception, "Conciliatory" was the label to depict terms such as "compromise," "win-win situation," and "teamwork is important". The third conception used the summary label "conviction" to describe sentiments such as "it must be done, whether they like it or not," "this is what is important, we should not settle for less," and "we must do otsic, we can do it!".

\section{Overview of Results}

Three different conceptions of alternative assessment were identified in terms of representing a progressively greater scope of understanding and using alternative assessment by 
TABLE 1: 3 Different ways of experiencing AA.

\begin{tabular}{|c|c|c|c|}
\hline Conceptions of AA & Conservative & Pragmatic & Progressive \\
\hline Focuses on & Status quo & Effectiveness & Sustainability \\
\hline Understands AA as & $\begin{array}{l}\text { AA is a luxury or a } \\
\text { distraction }\end{array}$ & $\mathrm{AA}$ is an improvement & $\begin{array}{l}\text { AA is an indictment of } \\
\text { current practices }\end{array}$ \\
\hline Uses AA to & $\begin{array}{l}\text { Supplement existing } \\
\text { practice but not relevant } \\
\text { to subject }\end{array}$ & $\begin{array}{l}\text { Complement existing } \\
\text { practice within subject }\end{array}$ & $\begin{array}{l}\text { Revamp assessment } \\
\text { practices beyond and } \\
\text { across subjects }\end{array}$ \\
\hline Power & $\begin{array}{l}\text { Tends to be conformist. } \\
\text { Tends to anticipate and } \\
\text { avoid resistance }\end{array}$ & $\begin{array}{l}\text { Conciliatory approach. } \\
\text { Works to placate and } \\
\text { accommodate } \\
\text { resistance }\end{array}$ & $\begin{array}{l}\text { Possess conviction of } \\
\text { critical need for AA. } \\
\text { Able to resist } \\
\text { compromise amidst } \\
\text { resistance }\end{array}$ \\
\hline
\end{tabular}

teachers. These three conceptions offer a lens for viewing how alternative assessment practices limit or enhance learning for students in qualitatively different ways. The following table illustrates the relations between the three conceptions of alternative assessment as a nested hierarchy see Table 1 .

A full account of the three conceptions of alternative assessment can be found in Tan [26]. The following is a summary of each conception.

5.1. Conservative Conception of Alternative Assessment. The conservative conception of alternative assessment may be understood as an unremitting focus on preserving the status quo in assessment practices exemplified by examinations. One of the prevailing notions of alternative assessment in Singapore amongst teachers is that it represents an alternative to examinations. Such a notion posits that alternative assessment should be judged in terms of national examinations.

However, teachers with a conservative conception of alternative assessment focus on preparing students for performing well in national examinations, and in that context alternative assessment is understood as a distraction because it does not contribute to better performance in the examinations. Such teachers do not dispute the utility of alternative assessment but maintain that it is a luxury they can afford only if it does not interfere in students' preparations for their examinations.

Consequently, the perception that alternative assessment lacks relevance to students' performance in examinations results in teachers (with a conservative conception of alternative assessment) sidelining alternative assessment as a supplement to existing "mainstream" assessment practices.

5.2. The Pragmatic Conception of Alternative Assessment. A pragmatic conception of alternative assessment differs from a conservative conception in that teachers focus on the effectiveness of assessment practices in bringing about the desired learning within each subject. Whilst a conservative conception views alternative assessment as a distraction to students preparing for their examinations, a pragmatic conception posits that all assessment practices (without being limited to the examinations) need to be improved in order to enhance its effectiveness in enhancing and constructing the desired learning within each subject.
Such teachers recognise the limitations of previous assessment practices for their subjects and utilise alternative assessment in a way that complements existing assessment practices. Teachers with a conservative conception keep two different types of assessment separate-traditional assessment mimics examinations and teaches to the test and alternative assessment that is so different from the examination that it has little utility for enhancing students' learning in the subject. In contrast, teachers with a pragmatic conception of alternative assessment design alternative and existing assessment practices to work in tandem with each other, in particular using alternative assessment to assist students with their learning in ways that traditional assessment fails to achieve.

5.3. The Progressive Conception of Alternative Assessment. Whilst teachers with a pragmatic conception are able to view alternative assessment and traditional assessment as complementary, they tend to view alternative assessment only within the confines of their subject and only to the extent of meeting learning needs within the academic year. In contrast, teachers with a progressive conception of alternative assessment focus on important learning needs that go beyond subject boundaries and which are sustainable beyond their academic year. Such teachers focus on using assessment to emphasise and bring about enduring learning and understanding. The focus is on understanding and using alternative assessment in ways that bring about learning that is sustainable beyond short terms needs, that is, beyond the academic year for which the teachers are teaching the students.

For such teachers, alternative assessment is understood as an indictment of current assessment and examination practices. Unlike teachers with a pragmatic conception, they do not seek to utilise alternative assessment to merely enhance the quality of learning and results that are measured and recognised in school and national examinations. Instead, they recognise that current assessment and examination practices do not fully depict the range nor sustainability of learning that is required by their students in their subsequent schooling or in their life. Hence, instead of using alternative assessment to supplement assessment practices within their subject (conservative conception) or to complement assessment practices for their subject (pragmatic conception), teachers 
with a progressive conception typically seek to revamp existing assessment practices within their remit and at times will collaborate with colleagues to bring about the same in other subjects.

\section{Three Conceptions of Power in Alternative Assessment}

Teachers' conceptions of alternative assessment offer contexts for understanding the different meanings and practices of power that are experienced when teachers provide their students with opportunities to enhance their own learning in alternative ways. Each conception of alternative assessment in this paper comprised of a specific number of teachers who share the defining characteristics of that conception. The interview transcripts of teachers within each conception are further analysed to identify instances of sovereign, epistemological, and/or disciplinary power.

6.1. Power in a Conservative Conception of Alternative Assessment. Teachers with a conservative conception have the weakest appetite for alternative assessment, regularly declining or avoiding alternative assessment opportunities when faced with anticipated resistance from others. Such teachers are willing to forgo alternative assessment, since they were not convinced of its inherent value as compared to traditional assessment in the first place. The following teachers are highly aware of the ever present scrutiny from parents which dissuades the adoption of new strategies such as alternative assessment.

\begin{abstract}
"The parents of students taking Higher Chinese class are always like that, you know. If you make one mistake in correcting students' work, they will write a letter of complaint the following day. I experienced several such cases in 2007." "Parents often exchange "intelligence" (information concerning the content and quantity of homework, for example, how many compositions their kids should write) at the school entrance when they are waiting for their children to show up."
\end{abstract}

Teachers who succumb all too easily in the face of parental resistance to any form of school innovation may be said to possess a sovereign notion of power. The idea of sovereign power arises from the context of explaining power relationships between sovereign rulers and subjects in the general course of history. Such articulations of power characterize power in episodic and interpersonal terms [23].

The actions of the person exercising sovereign power and the person subjected to that power must be explicit and obvious. For example, Dahl [46] viewed power as occurring where "A has power over B to the extent A can get B to do something that B would not otherwise do." Hence, power existed only if it could be seen to be exercised and power was seen to be exercised if its cause could be identified. In such absolute terms, one is either an agent of power (an authority) or a recipient who responds to power (subject).
In the context of school-based assessment, there are two parties relevant to the discussion of power: the teacher seeking to introduce alternative assessment and parents resisting any change to the status quo that may affect the academic results of their children. The power contest is a straightforward face off-whoever can stand their ground and protest more vigorously wins. However, because parents are treated as customers with direct access to MOE for appeals, the school and its teachers are frequently unable to implement any innovation that is unsupported by parents. Naturally, alternative assessment and its nondirect benefits to national assessment performance would face great opposition from parents.

However, it is still possible to implement some measure of alternative assessment despite parental resistance. This can be seen from the strategies and experiences of teachers with a pragmatic conception of alternative assessment.

6.2. Power in a Pragmatic Conception of Alternative Assessment. Teachers with a pragmatic conception are aware of parental objections or concerns over alternative assessment. However, they seek to be conciliatory and persuade parents to accept their alternative assessment initiatives. Effort is expended on keeping parents informed and making parents comfortable with what they are changing.

"If I were to name it "assessment with a difference", then parents would wonder what's the difference. But in formal assessment, they are more aware of it, because we have sent letters to them, so they know what we are into."

Likewise, they take special care to win over their colleagues.

"I think I still feel you got to encourage them no matter how negative they are. I feel the teachers need the support and resources. You give them the resources, they are willing to do it for you. But they do not want to do things where there is nothing there. They do not know where to source for things. So if you give them the resources like some lesson plans, resources how you conduct it, they can follow through and try it out. And when they are successful, they would actually try another...."

What makes a pragmatic teacher different from a conservative one in dealing with parental or collegial resistance? Naturally, pragmatic teachers would pick and choose their battles and would make decisions concerning the type and nature of alternative assessment against the level of resistance they can handle. In addition, teachers with a pragmatic conception of alternative assessment possess an awareness of their authority as teachers that come from knowing what needs to be learned in their respective subjects.

Unlike sovereign power which manifests as explicit actions, epistemological power relies on the control of knowledge. This makes it more insidious and therefore more prevalent. Epistemological power exists in the assessment process in terms of what can be assessed and how it is assessed. Knowledge is often said to be power, but who decides 
what constitutes knowledge in the first place? Epistemology concerns the question what counts as knowledge? Epistemological power derives from an individual or an institution claiming something they know to be valid and important knowledge and using that as a basis to assert their decisions. Power in this respect exists beyond explicit interpersonal episodes or confrontations.

An individual can be said to possess power without having to use it explicitly against another individual. When a body of persons collectively band together to retain and exercise their epistemological power, a hegemony is formed and perpetuated. Hegemonies are defined by Bocock [47] as occurring when the intellectual, moral, and philosophical leadership provided by the class which is ruling successfully achieves its objective of providing the fundamental outlook for the whole society.

A hegemony establishes and maintains its power though the continual consent of the masses to its leadership [48] and by manipulating the social context in which political contests are waged [49]. The teacher in this context is an institutional agent invested with authority (from the academic community) to make judgements about learners, and their power is legitimated in this way. Teachers who have the confidence to assert their subject knowledge may then exercise their collective power as a form of hegemony against parental resistance.

6.3. Power in a Progressive Conception of Alternative Assessment. Teachers with a progressive conception of alternative assessment are willing to move forward with their alternative assessment plans without first securing support from parents and colleagues. They are willing to expose students to alternative assessment without first waiting for students to be comfortable with such strategies. Hence, their introduction of alternative assessment is not dependent on the comfort level of students, colleagues, or parents but based on their conviction that alternative assessment is something critically important for their students' learning.

\section{"Interviewer: when you actually first started on concept maps and when you started to design your tasks differently, did you face any problems?}

Teacher: I think the students are discouraged like ... I just throw everything at them and leave it to them because I think our students are very used to spoon feeding from young. So I think they are not used to the style whereby the teacher throws everything at them and they have to just start somewhere. So I think they will whine. They will whine and complain and refuse to do the task... So we start from small and I guide them along... I draw the whole thing to them and explain, draw ... So then gradually they just somehow know how to do it."

"Teacher: Some parents practically said we were wasting their time, we were wasting the pupils' time doing this. We tried to explain to them that such thinking can never be tested in an examination... Because examinations only tested, in terms of academic knowledge and we tried to explain to them that having the knowledge does not mean that the child can apply. If the child proves that he can apply in any given problem, then that is when the child has really learnt. Then parents will say, but that's not how PSLE (Primary School Leaving Examination) is doing it... So if it's not done in PSLE, then you are wasting my time.

\section{Interviewer: Right. But you are still going to do it} again?

Teacher: We are still going to do it. We will never stop."

By claiming authority in knowing what is required in their subject, pragmatic teachers are able to utilise their epistemological power to placate students and persuade parents that alternative assessment is helpful to their children's learning (and examination performance) in the subject. However, such power is circumscribed by subject boundaries and even further by what is ultimately assessed in each subject.

In contrast, it is teachers who possess a progressive conception of alternative assessment that are able to exercise epistemological power in a way that permits alternative assessment beyond subject boundaries and in instances of learning that are not assessed in examinations.

Clearly, progressive teachers possess a conviction regarding alternative assessment that is able to withstand powerful resistance from parents and students. Whilst pragmatic teachers are able to utilise their epistemological power as subject teachers to introduce moderate forms of alternative assessment that are not resisted by parents, progressive teachers assert their epistemological power as teachers beyond their teaching subjects and examination result performance.

\section{Discussion}

It has been popular to advocate assessment practices as a means of "empowering" students in the assessment process. This is especially so for assessment purporting to have a formative purpose, that is, assessment that is designed primarily to enhance students' learning [50]. Various writers have argued that the primary purpose of alternative assessment is a formative one of enhancing students' learning. Maclellan [51] argues that the "primary beneficiary" of alternative assessment should be the learner and that alternative assessment "is viewed as having a primarily formative function." (p. 312).

Torrance [52] posits alternative assessment as a paradigmatic shift from traditional assessment and argues that such alternative assessment is instead a process that is firmly integrated with and positioned for the enhancement of teaching and learning. Likewise, the Assessment Reform Group argues for an alternative to traditional psychometric models of student assessment that emphasise "assessment for learning" that would focus on the process of seeking and interpreting 
evidence for use by learners and their teachers to decide where the learners are in their learning, where they need to go, and how best to get there [53].

Various writers have warned that it is naïve to assume that all students wish to be empowered in assessment $[54,55]$ and that all students are equally ready to exercise autonomy and self-regulation in assessment $[22,56]$. Both students and teachers bring with them learned notions of behaviour and power relations into the assessment process. Both may have been conditioned to accept entrenched roles in student assessment. In the case of younger learners, parents would also play an influential role in negotiating and challenging assessment decisions. Complex interrelationships between teachers, learners, and parents construct multiple opportunities for relationships of power between such parties. Teachers may find it difficult recognise and counter epistemological and disciplinary powers against them and their students/ parents in assessment practices. How and how well teachers address issues of power in order to use alternative assessment to benefit students' learning depend on how teachers understand and experience the different forms of power in alternative assessment.

The different experiences of power in alternative assessment may perhaps represent three increasingly broad scopes of alternative assessment discourse. In the conservative conception, teachers focus on retaining and exercising his or her commodity of sovereign power over students in the traditional and alternative assessment process.

In the pragmatic conception of alternative assessment, the focal awareness on the national examinations emphasises the academic as an agent or a proxy of the commodity of epistemological power as well as being a subject of the same epistemological power situated in and within high-stakes summative assessment. The curriculum defined by what is tested in examinations represents a point at which epistemological power is applied on the students (through the teacher) and on the teacher.

Teachers who understand power only as a commodity may emphasise how their power may be shared or distributed to students. The exercise of power by teachers at the expense of students is therefore viewed in a negative light. In contrast, teachers with a progressive conception of alternative assessment move beyond the meaning and practice of power as a commodity and tend to understand power as a discursive construct. The greater awareness of more critical aspects of alternative assessment is illuminated by dealing more reflexively with issues of power beyond the teacher's sovereign authority and the epistemological boundaries of the national curriculum/examination.

A progressive conception of power in alternative assessment indicates teachers' awareness of disciplinary notions of power which are not present in conservative and pragmatic conceptions which focus only on sovereign and epistemological power. Whilst notions of power as a commodity of sovereign and epistemological power seek to vest students with power in order for them to acquire knowledge, disciplinary notions of power acknowledge that the acquisition of knowledge may control its subjects. Hence, students may want to free themselves of power in order to self-acquire and selfassess their knowledge, but the acquisition of knowledge in turn renders the student governable by subjecting the student to measuring, categorising, normalising, and regulating [25].

\section{Conclusion}

This study suggests that meanings and practices of alternative assessment may be further understood in terms of teachers' experiences of power therein. Teachers who possess conservative or pragmatic conceptions of alternative assessment may tend to only understand power as quantifiable amounts of sovereign and epistemological power, respectively. In contrast, teachers who possess a progressive conception of alternative assessment also demonstrate awareness of the disciplinary effects of power in alternative assessment.

It would appear that teachers with a progressive conception of alternative assessment are reflexive and encourage their students to be reflexive, about existing assessment practices. The level of students' reflexivity in alternative assessment may therefore offer another alternative to evaluate alternative assessment in terms of power. Instead of comparing how much power is shared or distributed to students, alternative assessment in terms of power may be evaluated in terms of the extent that its practices allow or assist students to be reflexive about assessment practices. Further research on the scope for students to be reflexive in alternative assessment is suggested.

\section{References}

[1] M. Buhagiar, "Classroom assessment within the alternative assessment paradigm: revisiting the territory," Curriculum Journal, vol. 18, no. 1, pp. 39-56, 2007.

[2] P. Belanoff and M. Dickson, Eds., Portfolios: Process and Product, Heinemann, Portsmouth, UK, 1991.

[3] L. Darling-Hammond, "Setting standards for students: the case for authentic assessment," The Educational Forum, vol. 59, no. 1, pp. 14-21, 1994.

[4] C. Janisch, X. Liu, and A. Akrofi, "Implementing alternative assessment: opportunities and obstacles," The Educational Forum, vol. 71, no. 3, pp. 221-230, 2007.

[5] G. Wiggins, "Teaching to the (authentic) test," Educational Leadership, vol. 46, no. 7, pp. 41-47, 1989.

[6] E. Maclellan, "How convincing is alternative assessment for use in higher education?" Assessment \& Evaluation in Higher Education, vol. 29, no. 3, pp. 311-321, 2004.

[7] E. L. Baker, H. F. O’Neil, and R. L. Linn, "Policy and validity prospects for performance-based assessment," American Psychologist, vol. 48, no. 12, pp. 1210-1218, 1993.

[8] G. Wiggins, "A true test: toward more authentic and equitable assessment," Phi Delta Kappan, vol. 70, pp. 703-713, 1989.

[9] B. Worthen, "Critical issues that will determine the future of alternative assessment," Phi Delta Kappan, vol. 74, no. 6, pp. 444-454, 1993.

[10] J. Biggs, Teaching for Quality Learning at University, Open University Press, London, UK, 1999.

[11] M. Wilson and K. Sloane, "From principles to practice: an embedded assessment system," Applied Measurement in Education, vol. 13, no. 2, pp. 181-208, 2000. 
[12] L. Leach, G. Neutze, and N. Zepke, "Learners' perceptions of assessment: tensions between philosophy and practice," Studies in the Education of Adults, vol. 32, no. 1, pp. 107-119, 2000.

[13] M. Reynolds and K. Trehan, "Assessment: a critical perspective," Studies in Higher Education, vol. 25, no. 3, pp. 266-278, 2000.

[14] J. Heron, "Assessment revisited," in Developing Student Autonomy in Learning, D. Boud, Ed., Kogan Page, London, UK, 1988.

[15] P. Bourdieu, Language and Symbolic Power, Harvard University Press, Cambridge, Mass, USA, 1991.

[16] T. McMahon, "Using negotiation in summative assessment to encourage critical thinking," Teaching in Higher Education, vol. 4, no. 4, pp. 549-554, 1999.

[17] D. Boud, R. Cohen, and J. Sampson, "Peer learning and assessment," Assessment and Evaluation in Higher Education, vol. 24, no. 4, pp. 413-426, 1999.

[18] M. Paxton, "A linguistic perspective of multiple choice questioning," Assessment and Evaluation in Higher Education, vol. 25, no. 2, p. 109, 2000.

[19] E. Shohamy, "Democratic assessment as an alternative," Language Testing, vol. 18, no. 4, p. 373, 2001.

[20] L. Shepard, "The role of assessment in a learning culture," Educational Researcher, vol. 29, no. 7, pp. 4-14, 2000.

[21] P. Ramsden, Learning to Teach in Higher Education, Routledge, London, UK, 1992.

[22] K. H. K. Tan, "Does student self-assessment empower or discipline students?" Assessment \& Evaluation in Higher Education, vol. 29, no. 6, pp. 651-662, 2004.

[23] S. R. Clegg, Frameworks of Power, Sage, London, UK, 1989.

[24] J. M. Gore, "Foucalt's poststructuralism and observational education research : a study of power relations," in After Postmodernism: Education, Politics and Identity, R. Smith and P. Wexler, Eds., The Falmer Press, London, UK, 1995.

[25] R. Usher and R. Edwards, Postmodernism and Education, Routledge, London, UK, 1994.

[26] K. H. K. Tan, Reframing Alternative Assessment in Schools: A Research Based Perspective, Pearson South East Asia, Singapore, 2010.

[27] D. Hogan, P. Towndrow, and K. Koh, "The logic of confidence and the social economy of assessment reform in Singapore: a new institutionalist perspective," in Assessment of Abilities and Competencies in the Era of Globalization, E. Grigorenko, Ed., Springer, New York, NY, USA, 2009.

[28] A. Filer, Assessment: Social Practice and Social Product, Routledge Falmer, London, UK, 2000.

[29] K. Tan, "Assessment for learning in Singapore: unpacking its meanings and identifying some areas for improvement," Educational Research for Policy and Practice, vol. 10, no. 2, pp. 91103, 2011.

[30] K. Koh and A. Luke, "Authentic and conventional assessment in Singapore schools: an empirical study of teacher assignment s and student work," Assessment in Education: Principles, Policy \& Practice, vol. 16, no. 3, pp. 291-318, 2009.

[31] S. Stralberg, "Students, teachers and alternative assessment in secondary school: Relational Models Theory (RMT) in the field of education," Australian Educational Researcher, vol. 37, no. 1, pp. 83-106, 2010.

[32] T. T. Revital and H. Miedijensky, "A model of alternative embedded assessment in a pull-out enrichment program for the gifted," Gifted Education International, vol. 20, pp. 166-186, 2005.

[33] V. Klenowski, "Assessment for Learning revisited: an AsiaPacific perspective," Assessment in Education: Principles, Policy \& Practice, vol. 15, no. 3, pp. 263-268, 2009.
[34] P. Ashworth and U. Lucas, "Achieving empathy and engagement: a practical approach to the design, conduct and reporting of phenomenographic research," Studies in Higher Education, vol. 25, no. 3, pp. 295-308, 2000.

[35] F. Marton and S. Booth, Learning and Awareness, Lawrence Erlbaum, Mahwah, NJ, USA, 1997.

[36] M. Prosser and K. Trigwell, Understanding Learning and Teaching: The Experience in Higher Education, Open University Press, Milton Keynes, UK, 1999.

[37] F. Marton, G. Dall'alba, and E. Beaty, "Conceptions of learning," International Journal of Educational Research, vol. 19, pp. 277-300, 1993.

[38] G. Akerlind, "Variation and commonality in phenomenographic research methods," Higher Education Research \& Development, vol. 24, no. 4, pp. 321-334, 2005.

[39] F. Marton and A. Tsui, Classroom Discourse and the Space of Learning, Lawrence Erlbaum Associates, Hillsdale, NJ, USA, 2004.

[40] K. Koh and R. L. Velayutham, "Improving teachers' assessment literacy in Singapore schools: an analysis of teachers' assessment tasks and student work," Research Brief, vol. 9, no. 2, pp. $1-4,2009$.

[41] K. Trigwell, "A phenomenographic interview on phenomenography," in Phenomenography, J. Bowden and E. Walsh, Eds., pp. 62-82, RMIT Publishing, Melbourne, Australia, 2000.

[42] K. Trigwell, M. Prosser, and P. Taylor, "Qualitative differences in approaches to teaching first year university science," Higher Education, vol. 27, no. 1, pp. 75-84, 1994.

[43] J. Bowden, "Experience of phenomenographic research: a personal account," in Phenomenography, J. Bowden and E. Walsh, Eds., pp. 47-61, RMIT Publishing, Melbourne, Australia, 2000.

[44] F. Marton, "Phenomenography—a research approach to investigating different understandings of reality," Journal of Thought, vol. 21, pp. 28-49, 1986.

[45] J. Bowden, "The nature of phenomenographic research," in Phenomenography, J. Bowden and E. Walsh, Eds., pp. 1-18, RMIT Publishing, Melbourne, Australia, 2000.

[46] R. A. Dahl, “The concept of power," Behavioural Science, vol. 2, p. 201, 1957.

[47] B. J. Bocock, Hegemony, Tavistock, London, UK, 1986.

[48] A. Gramsci, Selections from the Prison Notebooks, Lawrence and Wishart, London, UK, 1971.

[49] J. A. Whitt, "Towards a class-dialectical model of power: an empirical assessment of three competing models of political power," American Sociological Review, vol. 44, pp. 81-100, 1979.

[50] P. Black and D. Wiliam, "Inside the black box: raising standards through classroom assessment," Phi Delta Kappan, vol. 80, no. 2, pp. 139-148, 1998.

[51] E. Maclellan, "How convincing is alternative assessment for use in higher education?" Assessment \& Evaluation in Higher Education, vol. 29, no. 3, pp. 311-321, 2004.

[52] H. Torrance, Authentic Assessment, Open University Press, Burmingham, UK, 1995.

[53] Assessment Reform Group, "Assessment for Learning: Research-based principles to guide classroom practice," 2002, http://www.assessment-reform-group.org/CIE3.PDF.

[54] L. Leach, G. Neutze, and N. Zepke, "Assessment and empowerment: some critical questions," Assessment and Evaluation in Higher Education, vol. 26, no. 4, pp. 293-305, 2001. 
[55] M. Taras, "Issues of power and equity in two models of selfassessment," Teaching in Higher Education, vol. 13, no. 1, pp. 81-92, 2008.

[56] N. Pope, "The impact of stress in self- and peer-assessment," Assessment \& Evaluation in Higher Education, vol. 30, no. 1, pp. 51-63, 2005. 


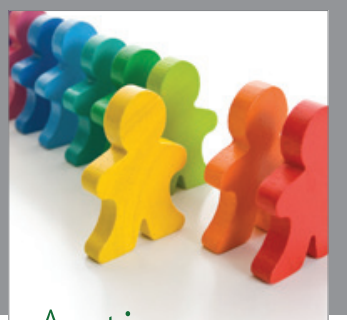

Autism

Research and Treatment
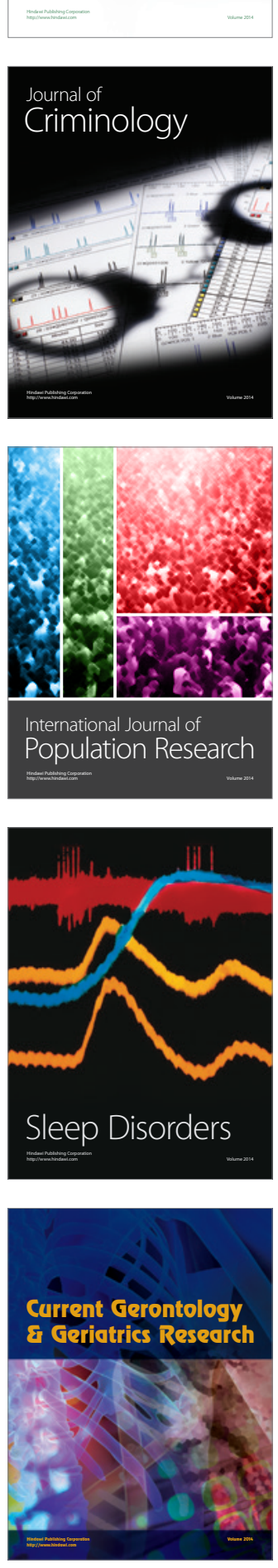
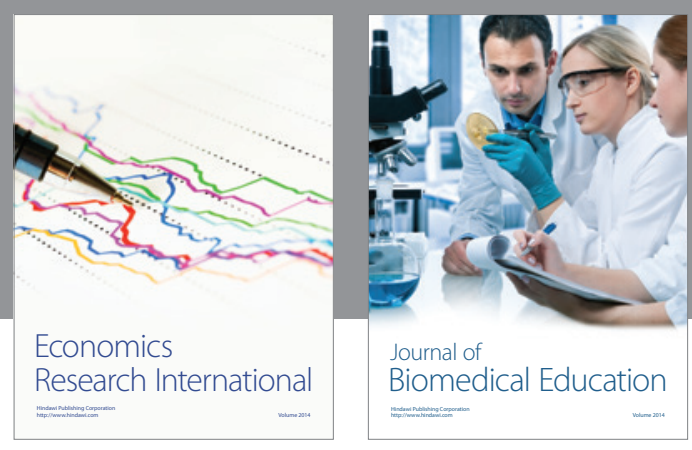

Journal of

Biomedical Education

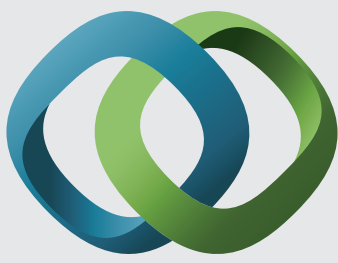

\section{Hindawi}

Submit your manuscripts at

http://www.hindawi.com
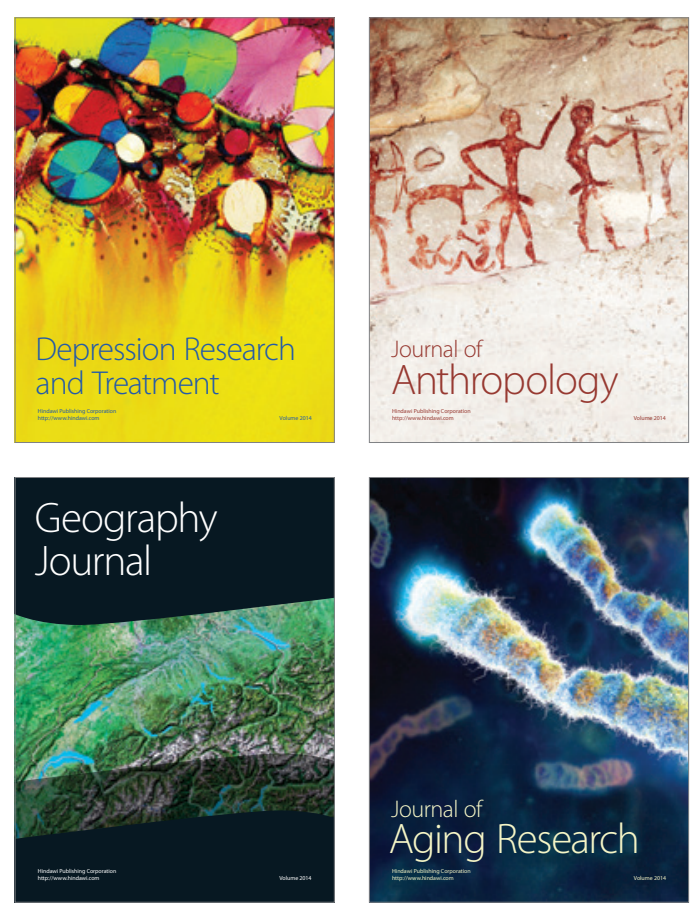

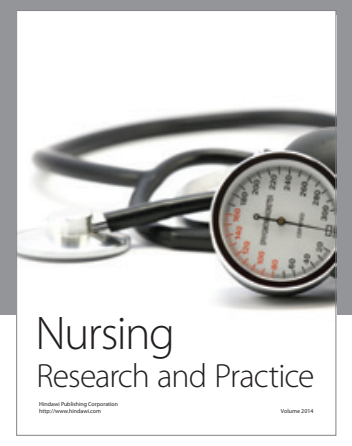

Nursing

Research and Practice

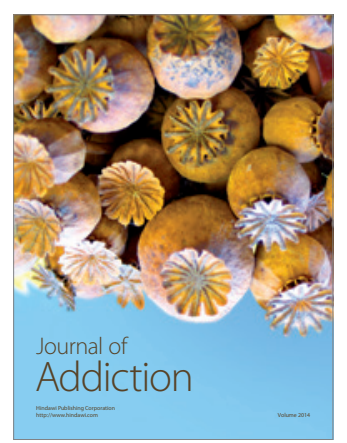

Child Development

Research

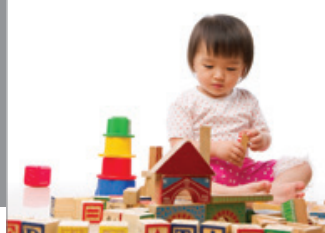

迥
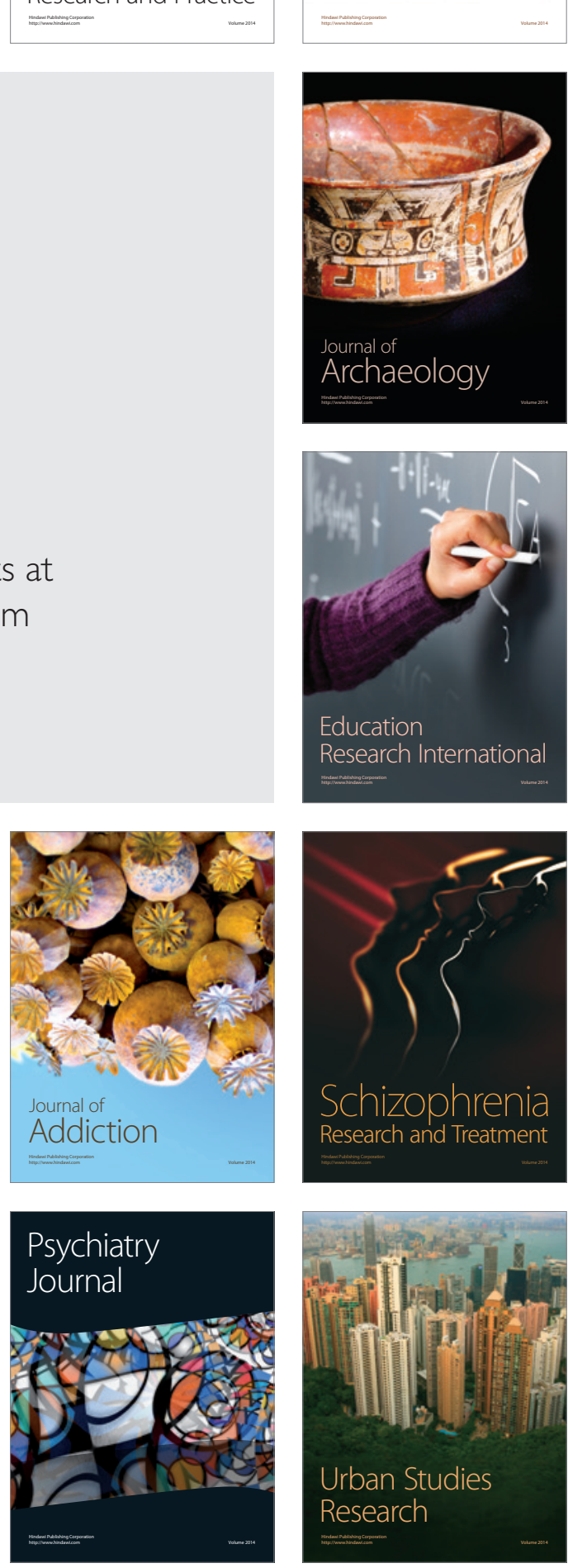